\title{
ACERCA DE LA NATURALEZA JURÍDICA DE LA COMPENSACIÓN ECONÓMICA. LA SITUACIÓN EN CHILE Y EN ESPAÑA
}

\author{
THE JURIDICAL NATURE OF ECONOMIC COMPENSATION \\ IN THE DIVORCE CONTEXT: CHILE AND SPAIN
}

\author{
Carlos Céspedes Muñoz ${ }^{*}$ y \\ DAVID VARGAS ARAVENA**
}

\begin{abstract}
RESUMEN: La compensación económica introducida por la Ley 19.947, Nueva Ley de Matrimonio Civil, se incorporó como una institución nueva para el ordenamiento jurídico nacional. Esta circunstancia, unida al hecho de que en su redacción definitiva no se han seguido las fórmulas exactas adoptadas por los sistemas que le sirvieron de modelo, conlleva la difícil labor de comenzar a delinear sus caracteres a partir de la breve reglamentación que la rige. Un problema semejante se plantea en España - uno de los referentes de la legislación chilena-, donde, no obstante estar consagrada legislativamente desde 1981, no existe un parecer unánime en orden a determinar el lugar que la compensación económica debe ocupar en el universo de las instituciones jurídicas. Así las cosas, en el presente trabajo sostenemos que la naturaleza jurídica de la compensación económica es el de una obligación legal de contenido patrimonial y que, fundada en la equidad, tiene por finalidad entregarle herramientas al cónyuge más débil para que pueda reiniciar dignamente su vida separada. Las concepciones alimenticias o indemnizatorias son insuficientes para explicar las particulares características de esta institución.
\end{abstract}

Palabras clave: Compensación económica, divorcio, naturaleza jurídica.

ABSTRACT: The economic compensation introduced by the New Chilean Matrimonial Act of 2004 was introduced as a new legal institution for the national juridical system. This circumstance, next to the fact that its drafting did not follow the exact lines adopted by the systems from which it was taken, bears the difficulty of outlining its character because it is guided only by the brief regulation that governs it. A similar problem arose in Spain -one of the referents to the Chilean legislation-, which, nevertheless was consecrated legistatively since 1981, don't exist as an unanimous vision about which place the economic compensation should take in the universe of the juridical institutions. We think the economic compensation has the nature of a legal obligation with patrimonial character, based on the equity, it purpose is to provide the weakest spouse with a tool to start over after the divorce. A different conception, such as the supporting or compensatory character, do not explain the very special cualities of this institution.

Key words: Economic compensation, divorce, nature.

* Licenciado en Derecho, Universidad Católica de la Santisima Concepción, Doctorando en Derecho Privado en la Universidad de Salamanca. Profesor de Derecho Civil de la Universidad San Sebastián. Correo: ccespedes@usal.es.

** Licenciado en Derecho, Universidad Católica de la Santísima Concepción, Doctorando en Derecho por la Universidad de Salamanca. Correo: davidvargasaravena@hotmail.com. 


\section{INTRODUCCIÓN}

Una de las novedades de la Ley 19.947, Nueva Ley de Matrimonio Civil (LMC), fue la consagración de la compensación económica como uno de los efectos patrimoniales que puede llevar consigo la sentencia de divorcio o nulidad.

Ahora bien, a estas alturas, ya no constituye nada nuevo afirmar que una de las grandes dificultades que trajo consigo la reglamentación actualmente vigente es su insuficiencia para explicar el fundamento y la naturaleza jurídica de esta institución. Las diversas soluciones dadas por la doctrina y la jurisprudencia tienden a tratar de encuadrar a esta figura dentro de las instituciones clásicas del derecho, sin reparar, quizás, que estamos frente a una simple prestación económica que procura dar una solución concreta a un problema específico: otorgar un mínimo de herramientas al cónyuge más débil para que recomience su vida luego de la ruptura.

Este problema también existe en la legislación española, cuyo ordenamiento fue uno de los modelos que tuvo el nuestro.

Por lo anterior, realizaremos un análisis conjunto de ambos ordenamientos que nos permitirán llegar a una misma conclusión: la compensación económica no es más que una obligación legal originada por la ruptura matrimonial, no encasillable en ninguna de las categorías formales que se han propuesto y fundamentada en la equidad.

\section{TESIS QUE SE HAN ESBOZADO}

A objeto de conocer las debilidades y fortalezas de las concepciones que se han elaborado para explicar la naturaleza jurídica de la compensación económica, haremos una revisión de tales tesis.

\section{LA COMPENSACIÓN ECONÓMICA COMO OBLIGACIÓN ALIMENTICIA}

En el sistema español parece negarse definitivamente el carácter alimenticio de la institución que analizamos, tanto por la doctrina ${ }^{1}$ como por la jurisprudencia ${ }^{2}$.

La confusión se origina en el hecho de que el artículo 97 del Código Civil español (CC español $)^{3}$ contiene circunstancias que la dotarían de carácter alimenticio, al menos

${ }^{1}$ García Cantero (1982) pp. 437 y 438; Roca (1999) pp. 146-149; Campuzano (1986) pp. 18 y ss; De la Haza (1989) pp. 17 y ss; Lalana (1993) pp. 27 y ss; Marín (1995) pp. 23 y ss; Martínez RODríGUeZ (2001) pp. 1 y ss; TORRERO (1999) pp. 142 y ss; MONTERO (2002) pp. 18 y ss; ZARRALUQUi (2003) pp. 117 y ss; MARTínEZ ESCRIBANO (2005) pp. 190 y ss.

${ }^{2}$ Lo cual es reafirmado en la ahora clásica sentencia del Tribunal Supremo español de 10 de febrero de 2005, Ponente Jesús Corbal Fernández (Repertorio Aranzadi RJ 2005/1133): “...Se quiere decir que está notoriamente alejada de la prestación alimenticia -que atiende al concepto de necesidad-, pero ello no supone caer en la órbita puramente indemnizatoria, que podría acaso suponer el vacío de los arts. 100 y 101 , ni en la puramente compensatoria que podría conducir a ideas próximas a la perpetuatio de un modus vivendi, o a un derecho de nivelación de patrimonios".

3 Artículo 97. El cónyuge al que la separación o el divorcio produzca un desequilibrio económico en relación con la posición del otro, que implique un empeoramiento en su situación anterior en el matrimonio, tendrá derecho a una compensación que podrá consistir en una pensión temporal o por tiempo indefinido, o en una prestación única, según se determine en el convenio regulador o en la sentencia. 
en parte ${ }^{4}$, como aquella relativa "al caudal y los medios económicos y las necesidades de uno y otro cónyuge"5; por lo que dispone el artículo 100 CC español, que admite la modificación de la compensación por "alteraciones sustanciales en la fortuna de uno u otro cónyuge"; y, por lo prescrito en el artículo 101 del mismo código, que establece como causa de extinción de la pensión ${ }^{6}$ al nuevo matrimonio del acreedor o su convivencia marital con otra persona, lo que eliminaría el estado de necesidad del cónyuge beneficiario ${ }^{7}$.

No obstante, las razones para desestimar este carácter alimenticio son sólidas:

a) Los presupuestos de su nacimiento. La compensación económica supone la existencia de un desequilibrio económico para un cónyuge, derivado de la separación o el divorcio ${ }^{8}$, que implique un empeoramiento en su situación anterior en el matrimonio en relación con la posición del otro. En cambio, la piedra angular del derecho de alimentos es el estado de necesidad del alimentario?

b) Su finalidad. Se ha sostenido que la pensión por desequilibrio va más allá de lo que puede exigirse en la obligación alimenticia, ya que contendría elementos indemnizatorios ${ }^{10}$ y compensatorios $^{11}$ : repararía el "daño objetivo" producido por la ruptura de la pareja, pretendiendo colocar al cónyuge perjudicado en una situa-

A falta de acuerdo de los cónyuges, el Juez, en sentencia, determinará su importe teniendo en cuenta las siguientes circunstancias:

1. Los acuerdos a que hubieran llegado los cónyuges.

2. La edad y el estado de salud.

3. La cualificación profesional y las probabilidades de acceso a un empleo.

4. La dedicación pasada y futura a la familia.

5. La colaboración con su trabajo en las actividades mercantiles, industriales o profesionales del otro cónyuge.

6. La duración del matrimonio y de la convivencia conyugal.

7. La pérdida eventual de un derecho de pensión.

8. El caudal y los medios económicos y las necesidades de uno y otro cónyuge.

9. Cualquier otra circunstancia relevante.

En la resolución judicial se fijarán las bases para actualizar la pensión y las garantías para su efectividad.

${ }^{4}$ LASARTE y VALPUESTA (1994) p. 1166.

${ }^{5}$ Roca (1984) p. 617; MARTínez Rodríguez (2001) p. 2.

6 En España, la compensación económica es denominada comúnmente como pensión compensatoria o pensión por desequilibrio. Con la Reforma de la Ley 15/2005 también se la comenzó a llamar compensación económica, ya que a la prestación única - una de sus modalidades- no se le puede denominar pensión por ser un término que denota periodicidad (ZARRALUQUi et al., 2005, p. 70; REBOlLEDO, 2005, p. 7).

7 RoCA (1984) p. 617 y 618.

${ }^{8}$ En el sistema español, según el artículo 97 CC, la compensación económica procede en caso de separación o divorcio.

9 Roca (1999) p. 147; CAMpuzano (1986) p. 19; De La HAZA (1989) p. 17 y 18; LALANA (1993) p. 28; Martínez Rodríguez (2001) p. 2; TOrrero (1999) pp. 146 y 147; Montero (2002) pp. 18 y 19 ; MARTÍNEZ ESCRIBANO (2005) p. 190.

${ }^{10}$ ROCA TRÍAs califica a la pensión compensatoria como "una indemnización por la pérdida de los costes de oportunidad alcanzados por un cónyuge durante el matrimonio (ROCA, 1999, p. 187)”.

11 Torrero Muñoz señala que "es un mecanismo corrector del perjuicio económico que a uno de los cónyuges ocasiona la separación o el divorcio (TORRERO, 1999, p. 150)”. 
ción de potencial igualdad de oportunidades laborales y económicas que habría tenido de no existir el vínculo matrimonial ${ }^{12}$. En cambio, el derecho de alimentos solo persigue superar el estado de necesidad del alimentario ${ }^{13}$.

c) Su contenido. La compensación económica es de mayor amplitud que el derecho de alimentos ${ }^{14}$ : no solo está destinada a cubrir necesidades vitales ${ }^{15}$, sino también, si es posible, conseguir la misma posición que el cónyuge acreedor gozaba durante el matrimonio ${ }^{16}$.

d) Su variabilidad. Los alimentos son esencialmente variables en proporción a la mayor o menor necesidad del que los recibe y a la mayor o menor fortuna del que los da (artículo 147 CC español). En cambio, la pensión compensatoria puede ser modificada "por alteraciones sustanciales en la fortuna de uno u otro cónyuge (artículo 100 CC español)”. De ahí la diferencia: su procedencia es excepcional y toma en cuenta las fuerzas patrimoniales de ambos cónyuges, no solo del deudor. A lo anterior, debemos agregar que la modificación de la pensión compensatoria no puede consistir en su aumento, pues el desequilibrio pretendido mitigar con esta prestación económica fue determinado y cuantificado al momento de producirse la ruptura matrimonial ${ }^{17}$, no teniendo ninguna influencia en su alza las circunstancias posteriores a ese evento ${ }^{18}$. Es decir, su techo quedó definitivamente fijado.

e) Su transmisibilidad. La obligación alimenticia cesa con la muerte del obligado a prestarlos (artículo 150 CC español). En cambio, la pensión compensatoria no se extingue por la muerte del cónyuge deudor, sin perjuicio de la facultad de los herederos de este de solicitar su reducción o supresión en los eventos previstos por la ley (artículo 101 CC español).

f) Su disponibilidad. Hemos afirmado que la pensión compensatoria se nos manifiesta como un derecho disponible, fundamentalmente porque la ley no ha prohibido su renuncia. En cambio, los alimentos son de ius $\operatorname{cogens}^{19}$, por lo que la obligación de prestarlos y el derecho a reclamarlos son irrenunciables (artículo 151 CC español) $)^{20}$.

g) El momento de su nacimiento. La obligación de proporcionar alimentos es exigible desde que los necesitare para subsistir quien tenga derecho a percibirlos,

\footnotetext{
12 Martínez Rodríguez (2001) p. 2.

13 Martínez Rodríguez (2001) p. 2.

14 Campuzano (1986) p. 19; De La Haza (1989) pp. 17 y 18; Martínez Rodríguez (2001) p. 2.

15 CAMPUZANO (1986) p. 19

16 De La HaZa (1989) p. 18; Martínez RodríGUeZ (2001) p. 2.

17 ZarraluQui (2003) p. 298.

18 MONTERO (2002) pp. 224 y ss. Similar fundamento se ha dado para negar la pensión compensatoria en los casos en que no existía el desequilibrio económico al momento de la ruptura de la convivencia. En este sentido, MARÍN (1997) pp. 60 y ss; RAMS (2000) p. 1025; CAMPUZANO (1986) p. 89; LACRUZ (1990) p. 250; Lalana (1993) p. 42; sentencia Audiencia Provincial de Salamanca de 15 de enero de 2001 (Repertorio Aranzadi AC 2001/677).

19 RocA (1999) p. 148.

${ }^{20}$ En el mismo sentido, entre otros, CAMPUZANO (1986) p. 20; LALANA (1993) p. 30; MARTínEZ RodríGUEZ (2001) p. 3.
} 
pero no se abonan sino desde la fecha en que se interponga la demanda (artículo 148.1 CC español). En cambio, la pensión por desequilibrio es exigible desde el momento en que se dicta la sentencia de separación o divorcio en la que se reconoce el derecho a percibirla ${ }^{21}$.

h) La posibilidad de sustituirse. El artículo 99 CC español autoriza la sustitución de la pensión fijada judicialmente por la constitución de una renta vitalicia, el usufructo de determinados bienes o la entrega de un capital en bienes o en dinero. En cambio, esta posibilidad no se ha reconocido a la obligación alimenticia, que se configura como una obligación duradera que existirá mientras se mantengan los presupuestos que le dieron lugar (artículo 148.2 CC español) ${ }^{22}$.

i) Su modalidad de cumplimiento. Los alimentos se presentan como una obligación de tracto sucesivo y de cumplimiento periódico ${ }^{23}$. En cambio, la compensación económica puede consistir en una pensión temporal, indefinida o en una prestación única.

Asimismo, los alimentos pueden cumplirse, a elección del deudor, pagando la pensión que se fije o recibiendo y manteniendo en su propia casa al que tiene derecho a ellos (artículo 149 CC español). Esta posibilidad es lógicamente imposible tratándose de la pensión por desequilibrio.

En Chile, parece existir unanimidad en la doctrina ${ }^{24}$ en considerar que la compensación económica no participa de la naturaleza jurídica de los alimentos, lo que ya se había zanjado en la discusión parlamentaria ${ }^{25}$. No obstante, se plantea alguna controversia en atención a que las cuotas en que se divide su pago se consideran alimentos para los efectos de su cumplimiento (artículo 66 inciso $2^{\circ}$ LMC) y, además, porque se incluyen como circunstancias para determinar la existencia del menoscabo económico y la cuantía de la compensación económica algunos criterios que implican modos de subsistencia, tales como la situación patrimonial de los cónyuges, entre otros ${ }^{26}$.

Se han dado las siguientes razones para negar el carácter alimenticio de la compensación económica en Chile:

a) Para determinar la compensación económica debe considerarse el empobrecimiento patrimonial del cónyuge beneficiario al haberse dedicado a tareas no lucrativas o haberlo hecho en menor medida. En cambio, los alimentos se fijan sobre la

21 De la Haza (1989) p. 19; Lalana (1993) p. 30; Martínez Rodríguez (2001) p. 3; Montero (2006) p. 210 y 211.

${ }^{22}$ Martínez Rodríguez (2001) p. 3.

${ }^{23}$ Martínez Rodríguez (2001) p. 3.

24 Pizarro (2004) p. 87; Gómez De La Torre (2005) pp. 7 y 8; Vidal (2004) p. 277; Domínguez ÁGUILA (2007) p. 88; CORRAL (2007) pp. 4 y 5.

${ }^{25}$ Así lo manifestaron los senadores Espina y Chadwick. Véase el Informe de la Comisión de Constitución, Legislación, Justicia y Reglamento del Senado, en segundo trámite constitucional, Boletín $N^{\circ}$ 1759-18, p. 198.

${ }^{26}$ Domínguez Hidalgo (2005) p. 11. En el mismo sentido, Pizarro (2004) p. 86; Gómez De La TORRE (2005) p. 7. 
base de las necesidades económicas del alimentario y las facultades económicas del alimentante ${ }^{27}$.

b) La compensación económica se fija por una vez y por siempre, no siendo posible su revisión por causa alguna ${ }^{28}$. Lo que no ocurre con la obligación alimenticia, los cuales pueden variar si han cambiado las circunstancias que legitimaron la respectiva demanda (artículo $332 \mathrm{CC}$ ).

c) Los alimentos encuentran su justificación en el deber de socorro que tienen los cónyuges. En cambio, ese deber no existe en la compensación económica, pues esta tiene lugar cuando el matrimonio ya ha terminado 29 .

d) No existe calificación expresa de ella como alimenticia: solo para efectos de su pago se la considera como tal, sin entrar a calificarla de esa forma ${ }^{30}$.

e) La discusión parlamentaria de la Ley de Matrimonio Civil le negó expresamente este carácter ${ }^{31}$.

Así las cosas, descartamos calificar a la compensación económica como obligación alimenticia, tanto en España como en Chile.

\section{LA COMPENSACIÓN ECONÓMICA COMO OBLIGACIÓN INDEMNIZATORIA Y/ O COMPENSATORIA}

Se ha sostenido en España que la pensión compensatoria, "para la doctrina mayoritaria, se trata de una indemnización tendente a reequilibrar la situación económica del cónyuge que como consecuencia de cesación de vínculo matrimonial, sufra una disminución patrimonial y este predominante matiz indemnizatorio debe calificar la naturaleza de la pensión, aunque la regulación positiva contenga evidentes contradicciones" 32 .

En este sentido, se le ha calificado como un caso de resarcimiento de daño objetivo, pero no en el sentido de responsabilidad civil ${ }^{33}$, ya que solo se considera el equilibrio entre los patrimonios de los cónyuges y no la participación de cada uno de ellos en las causas de la ruptura ${ }^{34}$. Sería "una indemnización por la pérdida de los costes de oportunidad alcanzados por un cónyuge durante el matrimonio, que se extinguen como conse-

\footnotetext{
27 Pizarro (2004) p. 87. En el mismo sentido, Domínguez ÁGuila (2007) p. 88; Vidal (2004) p. 277.

${ }^{28}$ Pizarro (2004) p. 87; Domínguez Hidalgo (2005) p. 11 y 12; Gómez De La Torre (2005) p. 8; VIDAL (2004) p. 277.

${ }^{29}$ GÓmEZ De La TORre (2005) p. 8.

30 Domínguez Hidalgo (2005) p. 11; Vidal (2004) p. 277.

31 Véase el Informe de la Comisión de Constitución, Legislación, Justicia y Reglamento del Senado, en segundo trámite constitucional, Boletín $\mathrm{N}^{\circ} 1.759-18$, p. 198.

32 ZARRALUQUi (2003) p. 124. La naturaleza indemnizatoria, al menos como calificación predominante de la pensión compensatoria, se ha sostenido, entre otros, por ROCA (1999) p. 187; MONTERO (2006) p. 204; CAÑete (2004) s/p; MARÍn (2006) p. 218; ZARraluqui (2003) p. 129; Martínez Escribano (2005) pp. 192 y 193; SEOANE (2005) p. 431.

33 ROCA (1999) p. 147. Sobre el particular, GARCía CANTERO señaló que "la norma presenta un fundamento objetivo, viniendo a consagrar una especie de responsabilidad sin culpa; más aún, por hecho lícito, cual es, en la legalidad vigente, el hecho de solicitar el divorcio (GARCía CANTERO, 1982, p. 431)”.

34 ROCA (1999) p. 191.
} 
cuencia del divorcio: mientras era eficaz, el matrimonio enmascaraba esta pérdida a través del deber de socorro; desaparecido el matrimonio, la pérdida se manifiesta con toda su crudeza y por ello debe existir la compensación... (RoCA, 1999, p. 187)”. "Persigue resarcir el daño que consiste en una situación de desequilibrio en detrimento de uno de los dos esposos, que queda en peor situación económica que el otro... (SEOANE, 2005, p. 431)”, lo que no equivale a igualar los patrimonios, lo que dejaría en claro la faceta indemnizatoria de la pensión compensatoria ${ }^{35}$.

Así, se ha dicho que "la finalidad de la pensión es la de resarcir un daño objetivamente evaluable en situaciones de desequilibrio económico que se manifiestan a consecuencia del fracaso del proyecto convivencial y por circunstancias concretas que en pro del proyecto común y en renuncia de intereses particulares concurren en un solo cónyuge y que, siendo irrecuperables de hecho y de derecho, y por tanto injustas, deben ser indemnizadas por el cónyuge benefactor de cara a evitar situaciones de enriquecimiento injusto o desigualdad de oportunidades ante el nuevo hecho que supone hacer una vida independiente (CAÑETE, 2004, s/p)”.

Este carácter indemnizatorio ha sido negado por cierto sector doctrinal, en base a los siguientes argumentos:

a) Teóricamente solo cabe pensar en dos tipos de indemnizaciones, las que tienen por fundamento la culpa del obligado y las que prescinden de ella, es decir, la denominada responsabilidad objetiva. Ninguna de ellas es predicable respecto de la pensión compensatoria, puesto que ninguna influencia tiene en ella la culpabilidad de los cónyuges y porque no existe el ejercicio de una actividad susceptible objetivamente de crear una situación de riesgo determinante de un peligro para terceros ${ }^{36}$.

b) El acreedor de las obligaciones indemnizatorias es el que ha sufrido un perjuicio como consecuencia de la realización de un hecho dañoso ejecutado por el agente del mismo. Esta situación no es predicable al caso que comentamos, pues esta prestación se concede con independencia de quien haya sido el responsable de la ruptura matrimonial ${ }^{37}$, pudiendo incluso ser titular de ella el causante de la misma.

c) El deudor de las obligaciones indemnizatorias es el agente del daño. Ello no acontece en la pensión compensatoria, pues incluso puede tener esta calidad quien no quiera la ruptura matrimonial y no sea el responsable de aquella, por las razones antes apuntadas ${ }^{38}$.

d) El módulo comparativo en las obligaciones indemnizatorias es el propio patrimonio del acreedor, que se aprecia antes y después de causada la lesión para la

35 MARÍN (1997) p. 90.

36 De La CÁmara (1985) p. 117 y 118.

37 DE LA HaZA (1989) p. 11 y 12.

38 De La Haza (1989) pp. 12 y 13. En este sentido, LALANA Del CASTILlo solo le atribuiría carácter indemnizatorio a la pensión si el deudor de la misma fuera el causante de la separación o ruptura del vínculo matrimonial (LALANA, 1993, p. 33). 
determinación de la existencia y cuantía del daño. En cambio, la pensión compensatoria pretende el equilibrio entre dos patrimonios de dos personas diferentes que han estado unidas por el vínculo matrimonial ${ }^{39}$.

e) En las relaciones indemnizatorias es necesario que se haya producido un daño, es decir, un detrimento que sufre una persona en sus bienes vitales o en su patrimonio. En el caso que nos ocupa, ninguno de los cónyuges sufre pérdidas materiales por el hecho de la separación o el divorcio, ya que mantendrán los mismos bienes a que tenían derecho constante matrimonio. Considerar como daño a la pérdida del derecho a participar en los bienes e ingresos del otro sería forzar la interpretación del daño que según la ley debe repararse ${ }^{40}$.

f) La referencia que hace el artículo 97 CC español a las circunstancias personales de los cónyuges, tales como las necesidades y los medios económicos de estos, no tienen importancia alguna para fijar la cuantía de las indemnizaciones, ya que esta se encuentra en directa relación con la magnitud del daño ${ }^{41}$.

g) La referencia que efectúa la misma disposición sobre las garantías para la efectividad del cobro de la pensión que debe fijar la resolución judicial. Una práctica judicial en este sentido sería excesiva para las indemnizaciones ordinarias ${ }^{42}$.

h) La posibilidad de modificar la pensión compensatoria que contempla el artículo 100 CC español. Ello sería imposible en sede judicial tratándose de una obligación indemnizatoria ${ }^{43}$.

i) La posibilidad de extinción de la misma conforme al artículo 101.1 del citado texto legal. No se vislumbra cómo la convivencia marital con otra persona, con o sin matrimonio, puede ser considerado como un hecho reparador del perjuicio que autoriza al cese de la pensión, máxime si esta norma no exige que la nueva convivencia le permita al acreedor vivir en igual situación económica que la que gozaba durante la vida en común del anterior vínculo matrimonial ${ }^{44}$.

Estos argumentos han puesto de relieve que la tesis indemnizatoria no es suficiente para explicar la naturaleza jurídica de la pensión compensatoria. En vista de ello, pero manteniendo esta calificación, se ha pretendido cambiar este concepto por el de "reparatorio" 45 o "compensatorio", no obstante ser términos sinónimos ${ }^{46}$.

\footnotetext{
39 De La HaZa (1989) p. 14.

${ }^{40}$ DE La HaZa (1989) pp. 14 y 15.

${ }^{41}$ De La HaZa (1989) p. 15.

42 DE LA Haza (1989) p. 15.

43 DE LA HaZA (1989) p. 15.

${ }^{44}$ De LA HaZA (1989) pp. 15 y 16.

45 En este sentido,

MARÍn (2006) p. 218. El carácter sinónimo lo pone de manifiesto ZARRALUQUI (2003) p. 121.

46 ZARRALUQUi (2003) p. 125. El mismo autor manifiesta que algunas Audiencias Provinciales utilizan los términos indemnizatorio, compensatorio y reparador como sinónimos: coinciden en la naturaleza jurídica indemnizatoria (ZARRALUQUI, 2003, p. 128).
} 
En esta línea, se argumenta que la diferencia entre indemnizar y compensar reside únicamente en la extensión de la reparación: el objetivo de la indemnización es la reparación total del daño; en cambio, compensar tiene un significado aritméticamente menos igualatorio, aunque su origen semántico sea el mismo ${ }^{47}$. Matizando la diferencia, se señala que no se trata de prevenir necesidades futuras, sino que se trata de compensar a quien más pierde con el divorcio ${ }^{48}$, de reparar las consecuencias de la ruptura matrimonial, sin entenderla como un derecho de nivelación o indiscriminada igualdad surgida automáticamente por el hecho del matrimonio ${ }^{49}$.

Y así hay quienes la califican derechamente como una compensación económica, en el sentido de ser un mecanismo corrector del perjuicio económico que a uno de los cónyuges ocasiona la separación o el divorcio ${ }^{50}$.

El carácter puramente compensatorio ha sido criticado, ya que de seguirse estrictamente "se llegaría a conclusiones de justicia ciega donde la simple celebración del matrimonio daría opción a los cónyuges a solicitar un derecho de nivelación de patrimonios, acaecida la separación, lo que indudablemente y dado el carácter primordialmente objetivo con que se ha concebido dicha pensión, sería una fuente de uniones matrimoniales guiadas por el interés material del económicamente débil" 51 . Esta posición se fundamenta en el hecho de que se debe distinguir entre el desequilibrio de los cónyuges al momento de la ruptura y la existencia del daño de carácter injusto capaz de ser resarcible por medio de la pensión: no todo desequilibrio origina el perjuicio o daño de carácter injusto $y$, por tanto, no toda situación de descompensación que pueda existir entre los cónyuges al momento de la ruptura es indemnizable o resarcible por medio de la pensión establecida en el artículo 97 CC español ${ }^{52}$.

De ahí que se propugnen soluciones mixtas o híbridas que contemplen al elemento indemnizatorio como uno de sus componentes. Así, la sentencia de la Audiencia Provincial de Córdoba de 25 de marzo de $1999^{53}$ la califica como compensatoria e indemnizatoria: “...la naturaleza será, pues, de carácter indemnizatorio para compensar al cónyuge al que la separación o divorcio produzca un perjuicio que afecte a su jerarquización de nivel de vida en relación con la del otro. En consecuencia la naturaleza compensatoria o indemnizatoria no son caracteres excluyentes o antagónicos sino complementarios, pues la viabilidad de la pensión que estudiamos será preciso en primer lugar una descompensación entre los cónyuges a causa de la separación o divorcio y en segundo lugar que el cónyuge en peor situación tenga derecho a un resarcimiento por el juego de las circunstancias que enumera el precepto en cuestión”.

\footnotetext{
47 ZARRALUQUi (2003) p. 125.

48 ROCA (1999) p. 147.

${ }^{49}$ MARÍn (2006) pp. 218 y 219.

50 TORRERO (1999) p. 150.

51 Sentencia Audiencia Provincial de Córdoba de 25 de marzo de 1999 (Repertorio Aranzadi AC 1999/597).

52 CAÑETE (2004) s/p.

53 Repertorio Aranzadi AC 1999/597.
} 
En esta misma línea se ha establecido su carácter compensatorio o reparador, como el que alude la sentencia de la Audiencia Provincial de Toledo de 8 de julio de 199754: "la pensión que regula el artículo 97 y siguientes CC tiene un carácter estrictamente compensatorio o reparador del desequilibrio patrimonial ocasionado por la separación o el divorcio en la posición económica de uno de los cónyuges respecto a la conservada por el otro, en relación con la que ambos venían disfrutando durante el matrimonio, que tiende específicamente a evitar que la ruptura o cesación de la vida conyugal suponga para uno de los esposos un descenso en el nivel de vida efectivamente gozado en el transcurso de esa relación, con independencia de la situación de necesidad mayor o menor del acreedor, dada la naturaleza esencialmente no alimenticia de la misma, pero teniendo en cuenta las expectativas de bienestar económico que la situación matrimonial pudiera haber ido creando en el cónyuge solicitante, en base a las condiciones de índole material bajo las que se hubiere desarrollado y conformado la vida conyugal".

También se ha dicho que junto con el elemento compensatorio existe un componente asistencial ${ }^{55}$. Este se apreciaría claramente en el caso de separación, puesto que, al pervivir el deber de socorro mutuo, debe entenderse que la pensión por desequilibrio engloba los alimentos del cónyuge. Y también en el caso de divorcio, ya que dentro de las circunstancias que deben considerarse están los medios y necesidades de uno y otro cónyuge, propias del derecho de alimentos. Por ello, se sostiene que "no se puede afirmar tajantemente ni el carácter indemnizatorio ni el alimenticio, porque la pensión compensatoria si bien tiene un carácter reparador, en sentido amplio, participa de diversas facetas, de múltiples aspectos, según los casos, lo que ha hecho que se califique de derecho condicional, relativo o circunstancial o de un derecho de naturaleza híbrida, mixta, etc. (MARín, 1995, p. 35).

No obstante, en este escenario, el componente alimenticio o asistencial de la pensión compensatoria es resistido: no puede señalarse que la compensación económica aglutina o integra los alimentos del cónyuge necesitado, ya que ambas prestaciones responden a realidades distintas y a conceptos legales diferentes ${ }^{56}$, más aún cuando se extingue la obligación alimenticia con el divorcio ${ }^{57}$.

Lo único claro es que las soluciones dadas por la doctrina y jurisprudencia españolas son insuficientes para explicar la naturaleza jurídica de esta institución. Más aún, esta afirmación se nos presenta diáfana cuando se señala que los términos "indemnizar", "compensar" y "reparar" coinciden en una naturaleza jurídica indemnizatoria ${ }^{58}$.

En Chile, la discusión es la misma y los argumentos bastante parecidos, con la diferencia de que la vertiente indemnizatoria no es compartida por una mayoría doctrinaria del número que la española. Los partidarios de esta tesis sostienen que la compen-

\footnotetext{
54 Repertorio Aranzadi ACAud 1997/1801).

55 LALANA (1993) p. 33.

56 CAÑETE (2004) s/p. Sostiene que es distinto afirmar que como "consecuencia del devengo de una pensión compensatoria puede ocurrir que no concurra el presupuesto esencial para el devengo de una pensión asistencial o de carácter alimenticio, como es el estado de necesidad o la indigencia”.

57 SEOANE (2005) p. 431.

${ }^{58}$ ZARRALUQUI (2003) p. 128.
} 
sación económica participa de una naturaleza indemnizatoria, pero no en el sentido de responsabilidad civil ${ }^{59}$, dado que no concurre el elemento daño ${ }^{60}$ y es irrelevante la culpa del cónyuge deudor ${ }^{61}$ para los efectos de su establecimiento.

Se ha sostenido que la naturaleza indemnizatoria provendría de la redacción del artículo 61 LMC, que habla de "compensar el menoscabo económico", lo que implicaría "una pérdida consumada o, al menos previsible, en razón de un hecho acaecido con anterioridad (PIZARRO, 2004, p. 88). Sería "una forma de resarcimiento de un cierto daño, es decir, de una cierta pérdida producida por el hecho de haber dedicado al esfuerzo de vida al cuidado de los hijos o a las tareas del hogar y que ha impedido, por lo mismo, una vida de trabajo con resultado económico y que permita así enfrentar la vida futura una vez producida la extinción del matrimonio (DOMínguez ÁGUILA, 2007, p. 89)"62.

En todo caso, hay quienes distinguen la "indemnización" de la "compensación". Este último concepto se diferenciaría del primero en cuanto a la extensión de la reparación, ya que en la compensación no es posible afirmar que la víctima quede completamente indemne porque es imposible restituirla en el valor dañado (como ocurre, por ejemplo, en el resarcimiento de los daños morales). Así, la suma que se concede al cónyuge demandante tiene un carácter compensatorio: solo otorga una satisfacción pecuniaria que pretende aplacar la desmejorada situación económica en que queda el cónyuge más débilib3.

Por otra parte, también se ha esbozado que la compensación económica participaría de la naturaleza jurídica de las denominadas "indemnizaciones por sacrificio" 64 -netamente distintas a las genuinas indemnizaciones de daños-, que son "compensaciones que las leyes atribuyen, en muchos casos, a determinados sujetos, como consecuencia de una pérdida, ablación o limitación forzosa de derechos subjetivos o como recompensa parcial del sacrificio que se exige a los titulares (DíEZ-PICAZO, 1999, p. 56 y 57)”. En Chile esta figura se conoce también con la denominación de "indemnizaciones por afectación lícita de derechos", con la cual se designa a la "suma que debe pagarse a quien debe soportar una carga o privación de un derecho por un imperativo jurídico justificado (CORRAL, 2003, p. 62 y 63)". Por lo tanto, al no ser responsabilidad civil, "el derecho a la prestación que se reconoce al cónyuge más débil se explica en último término en su sacrificio durante el matrimonio en provecho de la comunidad de vida que implica el matrimonio y el no hacer participar al otro cónyuge de su estatus económico resulta abiertamente injusto (VIDAL, 2004, p. 285 y 286)".

59 Pizarro (2004) pp. 89 y 90; Domínguez Hidalgo (2005) p. 12; Vidal (2004) pp. 280 y 281; Domínguez ÁGuila (2007) p. 89; CorRal (2007) pp. 4 y 5.

${ }^{60}$ Vidal (2004) p. 280; Domínguez ÁGuila (2007) p. 89.

61 Pizarro (2004) p. 89; Gómez De la Torre (2005) p. 8; Vidal (2004) p. 280 y 281; Domínguez ÁGuila (2007) p. 89.

${ }^{62}$ En el mismo sentido,

BARRIENTOS y NOVALEZ (2004) p. 420.

${ }^{63}$ Domínguez Águila (2007) pp. 88 y 89.

${ }^{64}$ VIDAL (2004) p. 285; CORRAL (2007) p. 5. 
En nuestro país, el carácter indemnizatorio se ha criticado por las siguientes razones:

a) No concurre el elemento esencial del daño. No sería correcto decir que el cónyuge beneficiario es víctima de este o que el cónyuge deudor sea el autor del mismo. El menoscabo económico que pretende reparar la ley proviene de las condiciones de la vida matrimonial, fundamentalmente de la opción que asumió el cónyuge beneficiario ${ }^{65}$.

b) No tiene ninguna influencia en la determinación de la existencia de la compensación económica la culpa del cónyuge deudor, pues procede en toda clase de divorcio y a favor del cónyuge que experimenta un menoscabo económico ${ }^{66}$.

c) No concurre el principio propio de la responsabilidad civil de restituir las cosas al estado anterior, ya que la compensación no busca colocar al cónyuge en la misma situación como si el matrimonio no se hubiese celebrado o su terminación no haya tenido lugar ${ }^{67}$.

d) La extensión de la indemnización de perjuicios está medida en función de la magnitud del daño, sin que tenga influencia alguna la buena o la mala fe del cónyuge deudor ${ }^{68}$, que es un factor a considerar para determinar la existencia del menoscabo económico.

En este entendido, la vertiente indemnizatoria, en su acepción amplia, tanto en España como en Chile se nos muestra también como insuficiente para explicar la naturaleza jurídica de la compensación económica.

\section{LA COMPENSACIÓN ECONÓMICA COMO OBLIGACIÓN LEGAL DERIVADA DE LA RUPTURA DE LA CONVIVENCIA MATRIMONIAL}

Ya hemos visto que la tesis que identifica a la compensación económica con el derecho de alimentos está absolutamente superada. Por otro lado, la tesis indemnizatoria se ve enfrentada a severas críticas, todas ellas atendibles y sólidas. Ante este escenario, tampoco la variante indemnizatoria que señala que la naturaleza jurídica de la pensión por desequilibrio sería la de una "compensación" se nos presenta como suficiente para delinear los caracteres de esta figura jurídica.

La importancia de determinar la calificación jurídica de la compensación económica la encontramos en la necesidad de determinar la legislación supletoria que le será aplicable ante la ausencia de las normas propias que la rigen. En este entendido, señalar que la naturaleza jurídica de la institución que comentamos corresponda a una "indem-

\footnotetext{
65 Vidal (2004) p. 280; DOMínguez ÁGUila (2007) p. 89.

66 Pizarro (2004) p. 89; Gómez De La TORre (2005) p. 8; Vidal (2004) pp. 280 y 281; Domínguez ÁGUila (2007) p. 89.

67 VidAL (2004) p. 281.

68 Pizarro (2004) p. 89; Gómez De La Torre (2005) p. 8.
} 
nización compensatoria” no agrega nada para estos efectos, puesto que, como hemos visto, se ha descartado que dicha reparación lo sea a título de responsabilidad civil: no es posible aplicar "las reglas y principios comunes de la responsabilidad civil por delito o cuasidelito para suplir sus vacíos o lagunas, ni como criterios de interpretación de los preceptos que la regulan (VIDAL, 2004, p. 286)”.

Por eso, descartamos la variante compensatoria de la pensión por desequilibrio, puesto que no presenta ninguna utilidad. Más aún, la expresión “compensar" en su sentido natural evoca una situación pasada ${ }^{69}$, lo que no se condice con la institución que comentamos, en que la situación futura del cónyuge más débil tiene importancia para determinar su cuantía.

Así, la respuesta correcta la obtendremos por descarte, siendo aplicable tanto para el ordenamiento español como al chileno.

En base a lo expuesto, sostenemos que la compensación económica tiene una naturaleza jurídica propia ${ }^{70}$ : es solo una obligación impuesta por la ley que se concede en los eventos previstos por ella, de contenido patrimonial y que, fundada en la equidad, tiene por finalidad entregarle herramientas al cónyuge más débil para que pueda reiniciar su vida separada:

a) Al ser una obligación legal ${ }^{71}$ estamos afirmando que su fuente normativa es la ley y la reglamentación específica que la rige ${ }^{72}$, la que también determina los eventos en que tiene lugar y los modos de establecerla.

En efecto, es la propia ley la que hace nacer la obligación concurriendo determinados supuestos de hecho previstos en ella misma ${ }^{73}$. Se trataría de aquel grupo de relaciones obligatorias que Díez-Picazo denomina "supuestos legalmente reglamentados", nacidos por el reconocimiento que hace la ley de "deberes primarios que la conciencia general hace derivar de un determinado contacto social entre personas (DíEZ-PICAZO, 1972, p. 394 y 395)”. Asimismo, la ley ha reglamentado su estatuto estableciendo, entre otros, sus requisitos de procedencia y los criterios para determinarla.

\footnotetext{
69 Según el Diccionario de la Lengua Española de la Real Academia, compensar significa "igualar en opuesto sentido el efecto de una cosa con el de otra. Dar algo o hacer un beneficio en resarcimiento del daño, perjuicio o disgusto que se ha causado". Es decir, repara una situación pretérita, que ya ocurrió.

${ }^{70}$ VidAL (2004) p. 287. En sentido parecido, GÓMEZ De LA TORRE (2005) p. 8, al sostener "que presenta características propias".

71 VIDAL (2004) p. 287; DE LA HAZA (1989) p. 16, quien la califica como "relación obligatoria del derecho de familia" cuya existencia emana de "un mandato legal que anuda el nacimiento de la obligación a una situación de hecho con independencia del comportamiento de las partes".

72 En este sentido, Domínguez HidALGO señala que "en cuanto a su régimen nos parece que, desde luego, no pertenece propiamente a la reparación a que apunta la responsabilidad civil y, por ende, no cabe aplicarle supletoriamente el régimen común de los daños. Ello resulta evidente si se tiene presente que los requisitos que se exigen para su procedencia no son los comunes a toda acción resarcitoria. Se rige, por tanto, por las normas que le regulan en la ley y es, a partir de ellas, que la doctrina y la jurisprudencia tendrán que ir configurando los principios que la disciplinan (DOMíngUeZ HidALGO, 2005, p. 12)”.

${ }^{73}$ Se trata de una obligación nacida de unos hechos legalmente reglamentados (LARENZ, 1958, pp. 61 a 63).
} 
Finalmente, en este orden de ideas, estamos afirmando que su legislación supletoria será la de las reglas generales en materia de efectos de las obligaciones ${ }^{74}$.

b) Que sea de carácter patrimonial significa que sus efectos no se extienden a la persona de los cónyuges o ex cónyuges, sino solo sobre sus relaciones económicas, por lo que ellos pueden disponer libremente de ella ${ }^{75}$.

c) Que el fundamento sea la equidad implica poner de manifiesto que si bien el divorcio disuelve el matrimonio, no lo destruye retroactivamente: ha existido una comunidad de vida que impide, en justicia, que cualquiera de los cónyuges se desentienda de la situación en que quede el otro al momento de producirse la ruptura $^{76}$.

En la literatura española se ha sostenido que "la equidad, en consecuencia, justifica la obligación; cimenta la utilización de elementos dispares no económicos, sino morales, para su cuantificación; permite la sucesión en la deuda, con limitaciones en la legítima, proporcionando una nota de orden familiar, excediéndose de la conyugal; debe exigir la contribución del acreedor para mitigar el efecto del desequilibrio, mediante, entre otras conductas, la búsqueda de los medios para adquirir una independencia económica; autoriza la extinción por nuevo matrimonio o convivencia semejante a la conyugal... (ZARRALUQUi, 2003, p. 129)”.

Con lo anterior, descartamos que sea la solidaridad postconyugal o el enriquecimiento sin causa el fundamento de esta prestación económica. En efecto, luego del matrimonio no existen deberes conyugales, por lo que no apreciamos cómo puede fundamentarse la pensión compensatoria en un deber inexistente ${ }^{77}$.

\footnotetext{
${ }^{74}$ VidAL (2004) p. 286. En España, las normas por las cuales se regirían las obligaciones legales serían las de los artículos 1101 y siguientes (PENA, 2004, p. 178). En Chile, serían las relativas a la denominada responsabilidad contractual, por ser el estatuto de aplicación general en esta clase de materias (ABELIUK, 2003, pp. 821 y 822).

75 Así, entre otros, GARCÍA RUBio señala que “...existen argumentos tanto procesales como sustantivos para sostener que las relaciones económicas entre los cónyuges son plenamente dispositivas y que los únicos acuerdos que podrían ser rechazados por ilegales serían los que contraríen los límites generales de la autonomía de la voluntad... (GARCÍA RUBiO, 2003, p. 1661, nota 24)”.

76 De La CÁmara (1985) p. 118. En el mismo sentido, Ragel (2001) pp. 215 y 216. ZarraluQUi SÁNCHEZ-EZNARRIAGA, luego de observar lo desconcertante de la naturaleza jurídica de la pensión compensatoria, señala que “...este carácter ambiguo e indefinido se justifica mejor si se considera la obligación como producto más bien del principio real que inspira o debe inspirar esta responsabilidad objetiva, que es la equidad (ZARRALUQUi, 2003, p. 129)". PASTOR VITA, en sentido similar, manifiesta que “...pese a poseer un carácter marcadamente indemnizatorio, trasciende los límites de la mera indemnización para pasar a tener, simultáneamente, un carácter compensatorio tendente a equilibrar, en la medida de lo posible, y en orden a razones de equidad, la desnivelación económica generada por la ruptura matrimonial... (PASTOR, 2003, p. 33)”. MARÍn GARCÍA DE LEONARdo también menciona a la equidad como fundamento de la pensión, aunque también habla de cierta solidaridad postconyugal (MARÍn, 1995, pp. 26, 27 y 28; MARÍN, 1997, p. 28).

77 De la CÁMARA ÁlVAREZ señala que “...ni se acaba de comprender el porqué de ese principio ni mucho menos que, en su virtud, la mujer divorciada pueda seguir viviendo a costa de su ex marido como si nada hubiese sucedido. Esto conduce, si el marido quiere volver a casarse, a una especie de poligamia económica, con todos los inconvenientes propios de la verdadera poligamia y sin ninguna de sus ventajas, en el supuesto que la poligamia tenga alguna (DE LA CÁMARA, 1985, p. 118)”.
} 
Con respecto al enriquecimiento sin causa, se señala que "difícilmente se puede argumentar diciendo que los papeles sociales que se atribuyen a cada cónyuge en el matrimonio y que son asumidos voluntariamente en sus relaciones internas y externas, producen un enriquecimiento injusto de uno de los cónyuges a costa del otro. Esto es posible argumentarlo en las relaciones de hecho dado que no existe base matrimonial, pero no puede ser una razón en el matrimonio"78. Por lo tanto, la existencia del matrimonio es la causa que excluye la aplicación de esta institución, máxime si el rol que asume cada uno de los cónyuges en esta comunidad de vida corresponde al ejercicio de una opción personal ${ }^{79}$.

d) Que tenga por objeto entregarle herramientas al cónyuge más débil para que pueda reiniciar su nueva vida separada, es constatar que esta prestación económica no pretende indemnizar ampliamente al cónyuge acreedor ni otorgarle un valor equivalente al lucro cesante sufrido durante la vida conyugal ${ }^{80}$. No pretende nivelar la situación patrimonial de ambos cónyuges ni mantener el mismo nivel de vida $^{81}$, sino dejarlo en condiciones para enfrentar dignamente la vida futura ${ }^{82}$.

Creemos que de esta forma se pueden solucionar una multiplicidad de interrogantes planteadas por la doctrina y la jurisprudencia, como la renuncia pactada en capitulaciones matrimoniales o en instrumento separado, las cuales serían admitidas sin inconvenientes; que el juez debe aprobar automáticamente los convenios reguladores en la parte que contempla la renuncia de la pensión compensatoria; y así, además, podremos enten-

78 ROCA (1999) pp. 186 y 187.

79 VidAL (2004) p. 286.

80 “.... No se trata de restituir un valor perdido por su equivalente exacto, como ocurre en la responsabilidad civil con la indemnización del daño patrimonial, en que la indemnización sustituye al interés económico perdido o afectado y se calcula en función del valor de este. Se trata solo de ofrecer una compensación, es decir, una satisfacción económica que mitigue la situación económica desmedrada del demandante (DoMíNGUEZ ÁGUILA, 2007, p. 89)”.

${ }^{81}$ En esta idea, ROCA TRÍAs rechaza que la pensión tenga la naturaleza de mantenimiento (ROCA TRÍAS, 1999, p. 188). La función no es igualar patrimonios dispares, ni "nivelar, en el sentido de una equiparación económica, sino reducir, en la medida de lo posible, los desequilibrios que engendran estas situaciones, teniendo en cuenta las situaciones concretas y el marco legal que las conforma (MARín, 2006, pp. 216 y 216)".

82 En cuanto a la finalidad se dice “... que no es otra que la de procurar el restablecer el equilibrio roto, en el bien entendido que no se trata de establecer una artificiosa igualdad en la posición económica de los esposos, ni se pretende una milimétrica equiparación entre los esposos, ni que el favorecido asuma la carga de sostener al otro cualquiera que sea el comportamiento de este, sino de reparar el sacrificio de uno de ellos poniéndole en una situación que le permita reiniciar su vida con las expectativas que se le habrían abierto de no haber contraído el matrimonio (SEOANE, 2005, p. 435)". CAMPUZANO TOME indica que el "equilibrio patrimonial en ningún caso debe de ser equiparado con "seguro de vida”, ya que lo que, en último término, debe de propugnarse es que a través de esta institución se posibilite la readaptación de aquella persona que como consecuencia de las circunstancias existentes durante el matrimonio se encuentra, una vez producida la crisis matrimonial, en una desfavorable situación económica en relación con la posición del otro esposo... (CAmpuzAno, 1994, pp. 899 y 900)". Sobre este punto, la I. Corte de Apelaciones de Antofagasta, en sentencia de fecha 29 de junio de 2007, ha señalado "que la compensación económica debe dejar al cónyuge más débil en una situación digna, modestamente proporcional a su posición social (rol 1317-2006, identificador LexisNexis Chile No 36577, www.lexisnexis.cl)”. 
der la diversidad de las circunstancias que se establecen para determinar su existencia, cuya razón de ser carece de respuestas prístinas de admitirse las vertientes alimenticias o indemnizatorias. Algunos de estos tópicos los analizaremos a continuación.

\section{SITUACIONES QUE SE SOLUCIONAN CON NUESTRA TESIS}

\section{RENUNCIA DE LA COMPENSACIÓN ECONÓMICA}

No existe consenso en la doctrina en orden a admitir que estamos en presencia de un derecho renunciable. Los que se han pronunciado específicamente por su renunciabilidad de manera general ${ }^{83}$ se fundamentan en el hecho de que tal derecho cabría en la fórmula general del artículo 12 CC. No obstante, durante la discusión parlamentaria, el Senador Viera-Gallo manifestó que "la renuncia podría aceptarse cuando los cónyuges negocian en un pie de igualdad, pero debe cuidarse que el cónyuge más débil no sea presionado a hacerlo. En todo caso, bien se podría sostener que son normas de orden público que no pueden renunciarse" 84 .

Donde tampoco existe acuerdo es si puede pactarse la renuncia de la compensación económica anticipadamente, en las capitulaciones matrimoniales otorgadas antes del matrimonio. Algunos ${ }^{85}$ no ven obstáculo en ello en atención a que se puede renunciar anticipadamente a los gananciales de la sociedad conyugal (artículo 1719 CC). Otros estiman que ello es improcedente, por cuanto un sector doctrinal ${ }^{86}$, considerándolo un derecho irrenunciable, hacen aplicable el artículo 21 de la LMC, que obliga al respeto a los derechos conferidos por las leyes que tengan el carácter de irrenunciables, o bien, como lo justifica otro autor ${ }^{87}$, por la circunstancia de que solo puede renunciarse al momento de demandar el divorcio o la nulidad, sea de forma expresa o tácita (cuando no la reclama), aplicando el principio que rige a la renuncia del crédito de participación de los gananciales del artículo 1792-20 CC, que impide su renuncia antes de que termine el régimen de bienes respectivo.

Estimamos que no estamos ante un derecho personalísimo, es decir, de aquellos que no pueden renunciarse, transferirse ni transmitirse, porque, de ser así, el legislador lo habría dicho expresamente. Así, por ejemplo, en el derecho de uso y habitación, derecho

83 Gómez De La Torre (2005) p. 18; Orrego (2004) p. 142. Puede citarse la sentencia de la I. Corte de Apelaciones de San Miguel de 6 de septiembre de 2007, rol 1286-2007, la cual, al pronunciarse sobre la validez de un convenio regulador, sostuvo "que la escritura pública en que incorporó el acuerdo de los cónyuges, importa el reconocimiento de estos respecto de la procedencia de la compensación económica y de la forma de pago de la misma, de acuerdo a las reglas de la sana crítica y en particular de la lógica, al Juez a quo, solo le resta considerar si es efectivo o no que se cumplen con los requisitos señalados en la Ley para dar lugar a la misma; norma que entonces, deberá siempre ser interpretada en armonía con los principios que informan el derecho de familia y especialmente el de proteger al cónyuge más débil, hecho ponderado por las partes al momento de fijarla, ya que se trata de una materia patrimonial, que por lo tanto es renunciable, más aún si se tiene presente la edad, y condiciones de los comparecientes del proceso (identificador LexisNexis Chile No 37211, www.lexisnexis.cl)".

${ }^{84}$ OrRego (2004) p. 142, nota 146.

85 GÓMEZ De LA TORRe (2005) p. 18.

${ }^{86}$ Domínguez Hidalgo (2005) p. 16 y 17.

${ }^{87}$ OrRego (2004) p. 142. 
personalísimo por excelencia, el legislador ha prohibido expresamente su transferencia y transmisión en el artículo 819 CC. Esta, creemos, es la razón de porque la ley estableció expresamente la prohibición de renunciar al crédito de participación en los gananciales, porque, de lo contrario, habría sido perfectamente renunciable ${ }^{88}$.

De otro punto de vista, si se puede renunciar a los gananciales de la sociedad conyugal anticipadamente, que, en teoría, son de mayor entidad que el crédito de participación, no avizoramos razones para negar la renunciabilidad anticipada de la compensación económica.

Ahora bien, tampoco podría argüirse la existencia de un principio general que prohíba la renuncia de estas prestaciones económicas que se derivan del régimen económico matrimonial, dadas las dispares soluciones que entregó el legislador respecto de la sociedad conyugal y la participación en los gananciales, según hemos visto.

Con respecto a la renuncia efectuada durante la tramitación de la demanda de divorcio o nulidad o con posterioridad a su determinación, no vemos inconveniente en ello, pues, es plenamente aplicable el artículo 12 CC $^{89}$.

Finalmente nos referiremos a la renuncia tácita, es decir, aquella que tiene lugar cuando no se ha solicitado de ninguna forma la pensión compensatoria. Creemos que es plenamente procedente, toda vez que el juez no puede concederla de oficio: no procede su concesión si no ha sido demandada. Esta característica se desprende inequívocamente del artículo 64 inciso final LMC, en virtud del cual "pedida en la demanda, en escrito complementario de la demanda o en la reconvención, el juez se pronunciará sobre la procedencia de la compensación económica y su monto, en el evento de dar lugar a ella, en la sentencia de divorcio o nulidad". A contrario sensu, si no se pide el juez no puede pronunciarse respecto de ella ${ }^{90}$.

Este aserto es refrendado por lo que señala el artículo 64 inciso $2^{\circ}$ del texto legal ya citado, el cual obliga al juez a informar a los cónyuges la existencia de este derecho durante la audiencia de conciliación, norma que solo tiene sentido en el entendimiento de que es el cónyuge afectado el que puede reclamarla91. De lo contrario, el juez podría hacerlo de oficio.

Por lo demás, la libertad y autonomía de la voluntad de los cónyuges se ve reflejada en la circunstancia de que los artículos 63 y 64 inciso $1^{\circ}$ de la LMC establecen que la compensación económica es un derecho cuyo establecimiento corresponde primeramente a los cónyuges y, subsidiariamente, al juez.

Asimismo, esta conclusión es corroborada por el hecho de que no puede bajo ningún respecto ser demandada con posterioridad al juicio de divorcio o nulidad, por cuanto rige en esta clase de procedimientos el principio de unidad de competencia, en

\footnotetext{
${ }^{88}$ CÉSPEDES (2008) s/pág.

${ }^{89}$ En el mismo sentido, OrRego (2004) pp. 142 y 140.

90 CÉSPEDES (2008) s/pág.

${ }^{91}$ Debe destacarse el carácter esencial de este trámite, que ha llevado a anular juicios por la omisión de esta información. Así, sentencia Corte de Apelaciones de Valdivia de 23 de julio de 2007, rol 530-2007, identificador LexisNexis Chile No 36677 (www.lexisnexis.cl); sentencia Corte de Apelaciones de Talca de 13 de septiembre de 2006, rol 720-2006, identificador Lexis Nexis Chile No35117 (www.lexisnexis.cl).
} 
virtud del cual el juez debe resolver todos los conflictos relativos a la familia y al régimen de bienes del matrimonio (artículo 89 LMC y artículo 17 de la Ley 19.968, que crea los Tribunales de Familia), cuyo fundamento fue precisamente no perpetuar los problemas familiares luego de terminado el juicio de separación o divorcio ${ }^{92}$.

Por lo demás, es un derecho que le corresponde al cónyuge, no al ex cónyuge.

\section{APROBACIÓN DEL PACTO DE COMPENSACIÓN ECONÓMICA ESTABLECIDO EN CONVENIO REGULADOR}

Conforme al artículo 63, "la compensación económica y su monto y forma de pago, en su caso, serán convenidos por los cónyuges, si fueren mayores de edad, mediante acuerdo que constará en escritura pública o acta de avenimiento, las cuales se someterán a la aprobación del tribunal".

Creemos que el tribunal no tiene facultades para rechazar este acuerdo en materia de compensación económica ${ }^{93}$. En efecto, el acuerdo de los cónyuges existirá, normalmente, cuando el divorcio sea solicitado de común acuerdo. Pues bien, como requisito de admisibilidad de la acción, el artículo 55 inciso $2^{\circ}$ de la LMC señala que "en este caso, los cónyuges deberán acompañar un acuerdo que, ajustándose a la ley, regule en forma completa y suficiente sus relaciones mutuas y con respecto a sus hijos. El acuerdo será completo si regula todas y cada una de las materias indicadas en el artículo 21 . Se entenderá que es suficiente si resguarda el interés superior de los hijos, procura aminorar el menoscabo económico que pudo causar la ruptura y establece relaciones equitativas, hacia el futuro, entre los cónyuges cuyo divorcio se solicita”.

De esta manera, esta norma nos reenvía al artículo 21 de la LMC para saber cuáles son las materias mínimas que debe contener el convenio regulador entre los cónyuges, para luego establecer si esos acuerdos son o no suficientes. De la sola lectura del señalado artículo 21 apreciamos que no aparece ninguna referencia a la compensación económica, por lo que este aspecto no podría ser objeto del juicio de suficiencia que deber realizar el tribunal respecto del convenio regulador presentado por las partes. Por lo demás, es imposible que dicha disposición contemple a la compensación económica, pues está ubicada en el párrafo $1^{\circ}$ del Capítulo III de la LMC, "De la separación de los cónyuges", en cuyo estado no procede esta prestación.

Así, el juez no podría rechazar el acuerdo por considerar insuficiente la compensación económica, ya que carece de facultades de pronunciarse en el extremo que comentamos. Debemos advertir que existen voces que señalan que el juez si tiene la atribución de revisar íntegramente el convenio, compensación incluida, en virtud del principio de protección del cónyuge más débil ${ }^{94}$.

Entonces ¿para qué efectos el artículo 63 LMC exige la aprobación del juez? Entendemos que se exige como condición de eficacia del derecho, es decir, sin la aproba-

\footnotetext{
92 Diario de Sesiones del Senado de Chile, sesión ordinaria No 11, de 9 de julio de 2003, p. 1615.

93 En este mismo sentido, VELOSO (2006) p. 185; CÉSPEDES (2008) s/pág.

${ }^{94}$ Domínguez Hidalgo (2005) p. 17; Corral (2007) pp. 22 y ss.
} 
ción judicial no podría exigirse el pago de la pensión compensatoria ${ }^{95}$. A similar solución ha llegado la doctrina ${ }^{96}$ respecto de la transacción sobre alimentos futuros del artículo 2451 CC, en virtud del cual "la transacción sobre alimentos futuros de las personas a quienes se deban por ley, no valdrán sin aprobación judicial; no podrá el juez aprobarla, si en ella se contraviene a lo dispuesto en los artículos 334 y 335”.

Por lo demás, esta homologación obligatoria por parte del juez parece tener justificación en un aspecto extrafamiliar: impide la transferencia de bienes entre cónyuges, normalmente prohibida ${ }^{97}$, para impedir el fraude a terceros. Imaginemos los casos en que se persiga el patrimonio del marido: la forma más fácil de eludir la acción de los acreedores sería traspasando los bienes a su mujer a título de compensación económica. Por otro lado, así también se cautela el interés fiscal, desde que, conforme a la Ley 20.239, de 8 de febrero de 2008, están liberadas del impuesto a la renta las compensaciones económicas. Así, con esta aprobación judicial se limita esta prestación solo a los eventos de nulidad o divorcio.

\section{CESIÓN Y TRANSMISIÓN}

Debemos distinguir las hipótesis de cesión y transmisión del derecho a la compensación económica respecto de aquella que ya se encuentre determinada, sea por homologación judicial del convenio regulador, sea por la respectiva sentencia.

Con respecto al derecho a la compensación, creemos que no es posible cederlo a terceros ni transmitirlo antes de su determinación, pues necesariamente debe ser fijado en un procedimiento de nulidad o divorcio, al cual no pueden acceder terceros distintos de los cónyuges ${ }^{98}$. Recordemos que la compensación económica está regulada en el Párrafo $1^{\circ}$ del Capítulo VII de la LMC, denominado "De las reglas comunes a ciertos casos de separación, nulidad y divorcio", con lo cual también obtenemos como corolario de que no puede decretarse en un procedimiento diverso a los ya indicados ${ }^{99}$. Esta conclusión es más estricta respecto de los herederos, pues ellos no podrán invocar el derecho a la compensación económica no demandado por el causante o decretado en su favor por sentencia judicial firme, puesto que en dicho caso el matrimonio habrá terminado por la muerte de uno de los cónyuges y no por divorcio o nulidad ${ }^{100}$.

\footnotetext{
95 En este sentido, CÉSPEDES (2008) s/pág.

96 VODANOVIC (1993) p. 88; RAMOS (2005) p. 532.

97 Por ejemplo, el artículo 1796 CC.

98 CÉSPEDES (2008) s/pág.

99 La compensación económica no procede en el caso de separación, dado que el vínculo matrimonial no se extingue y, con ello, se mantienen entre los cónyuges todas las prestaciones que recíprocamente se deben en calidad de tales. Por ello, se critican algunas impropiedades sistemáticas en que incurrió la LMC, como la que contempla a la compensación económica en el párrafo denominado "De las reglas comunes a ciertos casos de separación, nulidad y divorcio”, ya que no procede en el estado de separación. En este sentido, entre otros, BARRIENTOS y NOVAles (2004) p. 402; DomíngueZ Hidalgo (2005) p. 5.

$100 \mathrm{Al}$ efecto, sentencia de la Corte Suprema de fecha 7 de mayo de 2007, rol 5616-2006, la cual, invalidando de oficio la sentencia de divorcio respectiva, rechaza la demanda principal de divorcio y la recovencional de compensación económica por haber fallecido uno de los cónyuges durante la secuela del juicio, terminando, en consecuencia, el matrimonio por esta causa (identificador LexisNexis Chile No 36496, www.lexisnexis.cl).
} 
En relación a la compensación económica ya fijada, no existe ningún problema en disponer de ella y transmitirla de acuerdo a las reglas generales, en especial, dada la circunstancia de que se manifiesta en una suma única e inmutable que, en determinados eventos, puede dividirse en cuotas. Por lo demás, ello también puede efectuarse respecto del crédito de participación en los gananciales, que es un derecho de similar naturaleza al que estudiamos, al que la ley solo ha prohibido su renuncia o disposición anticipada al término del régimen (artículo 1792-20 Código Civil) ${ }^{101}$.

\section{CONCLUSIONES}

1. Las características de los ordenamientos chileno y español impiden configurar con absoluta nitidez la calificación jurídica de la compensación económica.

2. Esta problemática también se ha trasladado a la doctrina, que tampoco tiene un parecer unánime en cuanto a su naturaleza jurídica.

3. Las tesis alimenticias e indemnizatorias son insuficientes para explicar los particulares caracteres de la institución en comento, como hemos visto.

4. La compensación económica no es más que una prestación pecuniaria que procura dar una solución concreta a un problema específico, cual es la eventual posición desmejorada en que puede quedar el cónyuge más débil.

5. Así, no sería más que una obligación impuesta por la ley, que se concede en los eventos previstos por ella, de contenido patrimonial y que, fundada en la equidad, tiene por finalidad entregarle herramientas al cónyuge más débil para que pueda reiniciar dignamente su vida separada.

\section{BIBLIOGRAFÍA}

Abeliuk Manasevich, René (2003): Las obligaciones (Santiago, Editorial Jurídica de Chile, cuarta edición) 1148 pp.

Barrientos Grandón, Javier y NOvalez AlquÉZAR, Aranzazu (2004): Nuevo derecho matrimonial chileno (Santiago, Editorial Lexis Nexis Chile) 472 pp.

CAMPUZANO TOME, Herminia (1986): La pensión por desequilibrio económico en los casos de separación y divorcio. Especial consideración de sus presupuestos de otorgamiento (Barcelona, Librería Bosch) 286 pp.

Campuzano Tome, Herminia (1994) "Revisión jurisprudencial en torno a la figura de la pensión por desequilibrio: tendencia a su concesión con carácter temporal”, Actualidad Civil, no 4: pp. 897-908.

CAÑeTE QuezadA, Agustín (2004): "La pensión compensatoria: una visión de futuro". Disponible en: <www.porticolegal.com/pa_articulo.php?ref=180> [fecha de consulta: 20 septiembre 2007].

CÉSPEDES MuÑOZ, Carlos (2008): "El carácter dispositivo de la compensación económica”, Revista de Derecho y Ciencias Penales Universidad San Sebastián, No 10: en prensa.

101 OrRego (2004) pp. 139 y 140. 
Corral Talciani, Hernán (2007): "La compensación económica en el divorcio y la nulidad matrimonial". Disponible en: http://www.uandes.cl/dinamicas/ La_compensacioneconomica.HCorral.pdf [fecha de consulta 2 noviembre 2007].

CORRAL TAlCiAni, Hernán (2004): Lecciones de responsabilidad civil extracontractual (Santiago, Editorial Jurídica de Chile) 423 pp.

De La CÁMARA ÁlvareZ, Manuel (1985): "En torno a la llamada pensión compensatoria del artículo 97 del Código Civil”, en: VV.AA., Estudios jurídicos en homenaje a Tirso Carretero (Madrid, Publicaciones del Cincuentenario del Ilustre Colegio Nacional de Registradores de la Propiedad y Mercantiles de España) pp. 109-124.

De La Haza Díaz, Pilar (1989): La pensión de separación y divorcio (Madrid, La Ley) $163 \mathrm{pp}$.

Diez-PiCazo, Luis (1999): Derecho de daños (Madrid, Civitas) 367 pp.

DiEZ-PICAZO, Luis (1972): Fundamentos del Derecho Civil patrimonial (Madrid, Editorial Tecnos, reimpresión primera edición) volumen $1^{\circ}, 880 \mathrm{pp}$.

DomíngueZ ÁGuila, Ramón (2007): "La compensación económica en la nueva legislación de matrimonio civil”, Actualidad Jurídica, No15: pp. 83-92.

Domínguez Hidalgo, Carmen (2005): Compensación económica en la nueva ley de matrimonio civil (Santiago, publicación del Colegio de Abogados de Chile A.G.) 28 pp.

García CANTERO, Gabriel (1982): “Artículos 97 a 101”, en: Albaladejo, Manuel (director), Comentarios al Código Civil y Compilaciones Forales (Madrid, Editorial Revista de Derecho Privado) Tomo II, pp. 415-448.

García Rubio, María Paz (2003): "Los pactos prematrimoniales de renuncia a la pensión compensatoria en el Código Civil”, Anuario de Derecho Civil, vol. 56, No4: pp. $1653-1674$.

GÓmez De La Torre VArgas, Maricruz (2005): Compensación económica en la nueva ley de matrimonio civil (Santiago, publicación del Colegio de Abogados de Chile A.G.) $18 \mathrm{pp}$.

Lacruz Berdejo, José Luis (1990): Elementos de Derecho Civil. Derecho de Familia (Barcelona, Editorial Bosch, tercera edición actualizada) Tomo IV, volumen 1º, $598 \mathrm{pp}$.

Lalana Del Castillo, Carlos (1993): La pensión por desequilibrio en caso de separación o divorcio (Barcelona, José María Bosch Editor S.A.) 302 pp.

LARENZ, Karl (1958): Derecho de obligaciones (versión española y notas de Jaime SANTOS BRIZ, Madrid, Editorial Revista de Derecho Privado) 542 pp.

Lasarte Álvarez, Carlos, y Valpuesta Fernández, María del Rosario (1994): “Artículo 97”, en: LACRUZ BERDEJO, José Luis (coordinador) Matrimonio y divorcio. Comentarios al título IV del libro I del Código Civil (Madrid, Editorial Civitas S.A., segunda edición) pp. 1159-1186.

MARÍN GARCÍA DE LEONARDO, Teresa (1995): Los acuerdos de los cónyuges en la pensión por separación y divorcio (Valencia, Tirant lo Blanch) $112 \mathrm{pp}$.

MARÍn GARCíA DE LEONARDO, Teresa (1997): La temporalidad de la pensión compensatoria (Valencia, Tirant lo Blanch) 123 pp.

Marín García De LeOnardo, Teresa (2005): “Temporalidad de la pensión compensatoria en la Ley 15/2005 de 8 de julio”, en: DE VERDA y BEAMONTE, José Ramón 
(coordinador) Comentarios a las reformas de derecho de familia de 2005 (Navarra, Editorial Thomson Aranzadi) pp. 213-232.

MARTínez EscribanO, Celia (2005): "Comentarios del nuevo artículo 97 del Código Civil”, en: Guilarte GuTiÉRREZ, Vicente (director) Comentarios a la reforma de la separación y el divorcio (Ley 15/2005, de 8 de julio) (Valladolid, Editorial Lex Nova) pp. 185-226.

MARTÍNEZ RodRÍGUEZ, Nieves (2001): "Separación matrimonial, obligación de alimentos y pensión compensatoria”, Diario La Ley, No 5.417, 13 de noviembre, pp. 1-8.

MONTERO AROCA, Juan (2002): La pensión compensatoria en la separación y en el divorcio (la aplicación práctica de los artículos 97, 99, 100 y 101 del Código Civil) (Valencia, Tirant lo Blanch) 357 pp.

Montero Aroca, Juan, Flors Matíes, José y Arenas García, Rafael (2006): Separación y divorcio tras la Ley 15/2005 (Valencia, Tirant lo Blanch) 551 pp.

Orrego Acuña, Juan (2004): Análisis de la nueva ley de matrimonio civil (Santiago, Editorial Metropolitana) $195 \mathrm{pp}$.

PASTOR ViTA, Francisco (2003): "La renuncia anticipada a la pensión compensatoria en capitulaciones matrimoniales", Revista de Derecho de Familia, No 19 (abril): pp. 2555.

PenA López, José María (2004): "Función, naturaleza y sistema de la responsabilidad civil aquiliana en el ordenamiento jurídico español”, Revista de Derecho Privado, año No 88: pp. 174-208.

Pizarro Wilson, Carlos (2004): "La compensación económica en la nueva Ley de Matrimonio Civil chilena", Revista Chilena de Derecho Privado, No3: pp. 83-104.

RAGEL SÁnCHEZ, Luis (2001): Estudio legislativo y jurisprudencial de Derecho Civil: familia (Madrid, Dykinson) 630 pp.

Ramos Pazos, René (2005): Derecho de Familia (Santiago, Editorial Jurídica de Chile, quinta edición actualizada) $781 \mathrm{pp}$.

RAMS AlBESA, Joaquín (2000): "La pensión compensatoria (artículos 97 a 101)", en: RAMS AlBesA, Joaquín (coordinador) Comentarios al Código Civil (Barcelona, José María Bosch Editor) tomo II, volumen 1º, pp. 1023 a 1035.

Rebolledo VARela, Ángel (2005): "La compensación económica del artículo 97 CC (LEG 1889, 27) en la Ley 15/2005, de 08 de julio (RCL 2005, 1471)”, BIB 2005/ 2647 en www.westlaw.es. También en Aranzadi Civil, No3, pp. 2347-2367.

RoCa TRÍAs, Encarna (1999): Familia y cambio social (De la "casa" a la persona) (Madrid, Civitas) $277 \mathrm{pp}$.

Roca TríAs, Encarna (1984): “Artículo 97”, en: VV. AA., Comentarios a las reformas del derecho de familia (Madrid, Editorial Tecnos S.A.) volumen I, pp. 615 a 629.

SEOANE Prado, Javier (2005): "Prestaciones económicas: derecho de alimentos y pensión compensatoria”, en: GonZÁlez Poveda, Pedro y GonzÁlvez Vicente, Pilar (coordinadores) Tratado de Derecho de Familia. Aspectos sustantivos y procesales (Madrid, Sepín Editorial Jurídica) pp. 365 a 442.

Torrero Muñoz, Magdalena (1999): Las crisis familiares en la jurisprudencia. Criterios para una mediación familiar (Valencia, Editorial Práctica de Derecho) 184 pp. 
Veloso Valenzuela, Paulina (2006): "Algunas reflexiones sobre la compensación económica", Actualidad Jurídica, No 13: pp. 171-188.

VIDAL Olivares, Álvaro (2004): "La compensación económica en la Ley de Matrimonio Civil. ¿Un nuevo régimen de responsabilidad extracontractual?”, Revista de Derecho Universidad de Concepción, No 215-216: pp. 265-287.

Vodanovic H., Antonio (1993): Contrato de transacción (Santiago, Editorial Jurídica ConoSur Ltda., tercera edición) 208 pp.

ZARRALUQUI SÁNCHEZ-EZNARRIAGA, Luis (2003): La pensión compensatoria de la separación conyugal y el divorcio (Valladolid, Editorial Lex Nova, segunda edición) 481 pp.

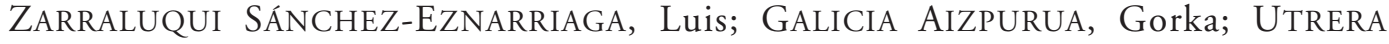
Gutiérrez, José Luis y Elósegui Sotos, Aurora (2005): Actualización del derecho de familia y sucesiones (Madrid, Dykinson) $192 \mathrm{pp}$.

\section{DOCUMENTOS}

Informe de la Comisión de Constitución, Legislación, Justicia y Reglamento del Senado, en segundo trámite constitucional, Boletín N¹759-18, p. 198.

Diario de Sesiones del Senado de Chile, sesión ordinaria No 11, de 09 de julio de 2003, p. 1615.

\section{NORMAS CITADAS}

CHILE

Código Civil: artículos 12, 332, 819, 1719, 1792-20, 2451.

Ley 19.947, Nueva Ley de Matrimonio Civil. Diario Oficial, 17 mayo 2004: artículos $21,55,61,63,66,89$.

Ley 19.968, Tribunales de Familia. Diario Oficial, 30 agosto 2004: artículo 17.

ESPAÑA

Código Civil: artículos 97, 99, 100, 101, 147, 148, 149, 150, 151.

\section{SENTENCIAS}

\section{CORTE Suprema CHILE}

Sentencia de 7 de mayo de 2007, rol 5616-2006 (identificador LexisNexis Chile No 36496, www.lexisnexis.cl).

\section{Cortes de Apelaciones Chile}

Sentencia de la I. Corte de Apelaciones de Talca de 13 de septiembre de 2006, rol 720 2006, identificador Lexis Nexis Chile No35117 (www.lexisnexis.cl).

Sentencia de la I. Corte de Apelaciones de Antofagasta de fecha 29 de junio de 2007, rol 1317-2006, identificador Lexis Nexis Chile No 36577, www.lexisnexis.cl”. 
Sentencia de la I. Corte de Apelaciones de Valdivia de 23 de julio de 2007, rol 5302007, identificador LexisNexis Chile No 36677 (www.lexisnexis.cl).

Sentencia de la I. Corte de Apelaciones de San Miguel de 6 de septiembre de 2007, rol 1286-2007 (identificador LexisNexis Chile No37211, www.lexisnexis.cl)”.

\section{TRIBUNAL SUPREMO ESPAÑA}

Sentencia de 10 de febrero de 2005, Ponente Jesús Corbal Fernández (Repertorio Aranzadi RJ 2005/1133).

\section{Audiencias Provinciales España}

Sentencia Audiencia Provincial de Toledo de 8 de julio de 1997 (Repertorio Aranzadi ACAud 1997/1801).

Sentencia Audiencia Provincial de Córdoba de 25 de marzo de 1999 (Repertorio Aranzadi AC 1999/597).

Sentencia Audiencia Provincial de Salamanca de 15 de enero de 2001 (Repertorio Aranzadi AC 2001/677). 